\title{
O Consumo de Queijo como Referência para a Análise do Mercado de Qualidade do Produto ${ }^{1}$
}

\author{
Marie Anne Najm Chalita²
}

\begin{abstract}
Resumo: Este trabalho situa-se na perspectiva teórica da Sociologia Econômica e algumas contribuições teóricas da economia industrial, procurando inserir a importância do consumo na análise do mercado de qualidade do queijo. Seu objetivo é refletir a relação entre qualidade e estratégias de segmentação industrial e nichos de consumo, a partir da classificação de grupos de consumidores do produto sobre as relações estabelecidas entre alimentação-alimento. A investigação foi realizada através de aplicações de questionário fechado em mercados municipais da cidade de São Paulo, além de algumas empreendidas em redes sociais ampliadas. Sobre os dados obtidos, procedeu-se à análise multivariada, elencada a classe econômica como variável dependente. Os resultados apontam para uma relação com a qualidade do alimento, como singularidade, na razão inversa a da pirâmide social, destacando-se as Classes B e C. Conclui-se que faltam dispositivos formais de qualidade na estrutura dominante do mercado queijeiro que abriguem as noções de qualidade expressas pelos consumidores. Estas noções agem favoravelmente na valorização dos queijos artesanais nacionais como via de diminuição da dependência do País em relação às denominações estrangeiras dos queijos, de aumento do consumo de queijos em geral, de visibilidade do mercado de qualidade do produto no País e no cenário internacional.
\end{abstract}

Palavras-chaves: Consumo, queijo, mercados de qualidade.

\begin{abstract}
This paper is placed on the theoretical perspective of Economic Sociology and some contributions of the industrial economy in order to express the importance of consumption in the analysis of quality market of cheese. It intends to reflect the relation between quality and industrial segmentation and niches of consumption strategies through the classification of groups of cheese consumers on established relations between feeding-food. The investigation was based on applications of closed questionnaire in municipal markets of São Paulo, beyond some undertaken in extended social nets. Upon the data, it was proceeded multivaried analysis considered economic class as dependent

1 Trabalho resultado de pós-doutoramento sob supervisão do Prof. Dr. Ricardo Abramovay na FEA/ USP e financiado pela Fapesp/SP. Rodagem do Software SPSS: Prof. Dr. Dirceu da Silva (Unicamp/ Faculdade de Educação).

2 Doutora em Sociologia pela Université de Nanterre/Paris e Universidade Federal do Rio Grande do Sul. Pesquisadora Científica do Instituto de Economia Agrícola/APTA/SAA/SP. E-mail: mariechalita@iea.sp.gov.br
\end{abstract}


variable. Results show a relation with the food quality inverse of social pyramid, mainly B and C Classes. In consequence, it is pointed the lack of formal devices of quality in the dominant structure of cheese market that could express quality notions from consumers. This conclusion points towards the valorization of Brazilian handmade cheeses as a way to reduce the dependence on foreign cheese denominations, to the increase of cheese consumption in general and to the visibility of quality market of the product, both in Brazil and in the international scenario.

Key-words: Consumption, cheese, quality markets.

Classificação JEL: Z3.

\section{Introdução}

O consumo alimentar vem crescentemente ampliando seus significados e feições em torno da qualidade dos alimentos e da cerimonialização das refeições. Evadindo-se da esfera privada enquanto manifestação de sociabilidades e vivências íntimas, vem ocupando a cena pública em torno de posições sobre o que vem a ser o "bom" alimento, sua origem, a forma de incorporá-lo, a forma de servi-lo. Padrões de consumo, pelo seu enraizamento na esfera social mais ampla do que as fronteiras do mercado de um determinado produto, traduzem disputas por padrões de historicidade sobre a alimentação humana dentro de uma tendência atual ditada pela indústria agroalimentar, de padronização e despersonalização do alimento. Estas disputas evidenciam gostos, lógicas unificadoras que regem as preferências. Dentre as condições sociais nas quais eles são forjados está a relação entre alimentação-alimento. Os agenciamentos dos consumidores influenciam a essência e direção do mundo material, corroborando com a crítica estética e ética dos mercados, ao criar novas premissas de legitimação social.

Uma das principais características do mercado de queijos no Brasil são as definições adotadas para diferenciar queijos comuns, queijos finos (ou especiais) e queijos artesanais. Os queijos comuns são aqueles padronizados, que não apresentam sabor, aroma e textura destacáveis, produzidos pela indústria, incluindo aqueles que portam denominações regionais, conforme as adotadas tradicionalmente pela produção artesanal. Já os finos ou especiais são aqueles produzidos em pequena escala de produção pela indústria, visando responder eminentemente a uma estratégia comercial de manutenção de preços elevados e de diferenciação apenas de forma, tamanho e rotulagens. Estes queijos diferenciados portam os nomes-tipos genéricos de queijos europeus que não gozam de certificação de origem restritiva nos respectivos países. Esta fatia do mercado de queijos finos no Brasil tem forte dependência da flutuação dos queijos importados industriais de mesmo nome. A produção de queijos artesanais tem estreita relação com a qualidade dos solos, matérias-primas, alimentação dos animais e práticas culturais consideradas tradicionais, portanto, oposta aos produtos tecnológicos. Porém, suas especificidades não possuem visibilidade mercadológica, haja vista o acento dado aos processos de certificação que garantem apenas a rastreabilidade sanitária do produto com o objetivo de tirar-lhes da clandestinidade, situação em que se encontram $40 \%$ do total da produção nacional de queijos (CHALITA et al., 2010).

A comercialização dos queijos artesanais assenta-se dominantemente em redes de distribuição informais, esparsas ou próximas ao local de produção, sem renda de qualidade garantida (MENEZES, 2009; VITROLLES et al., 2006), a não ser no caso de produtores isolados quando estes acessam redes de comercialização de excelência ${ }^{3}$. Por serem mais baratos, lhes é imputado uma imagem de serem queijos de pior qualidade, ainda que, em muitos casos, a falta de políticas específicas visando sua valorização não possibilite investimentos

3 Exemplo pode ser visto em Caetano e Valente (2010). 
na aproximação dos elos da cadeia de produção e comprometa, de fato, padrões de conformidade mínimos. Eminentemente produzidos por pequenas ou médias empresas ou elaborados com algum grau associativo, o maior desafio é a concorrência com os produtos industrializados.

A segmentação do mercado de qualidade entre queijos finos (ou especiais) e queijos comuns-padronizados no Brasil tem pouca distinção em termos dos agentes que o produzem, contrariamente ao mercado mundial de queijos, que se pauta pela tradição na produção artesanal, inimitabilidade e vinculada a uma determinada área geográfica. É justamente o pequeno vínculo com as características do que conceitualmente é chamado de produção artesanal que faz com que o mercado queijeiro seja competitivo, isto é, responda a uma maior escala de produção, perdendo o País em termos de tornar visível a diversidade do alimento. A valorização dos queijos artesanais pela sua raridade e tipicidade agiria como fator indutor da ampliação da escala de produção dos queijos finos ou especiais, por um lado, estimulando o consumo da qualidade dos queijos de forma geral. Isto, sem dúvida alguma, beneficiaria a indústria nacional e resultaria em melhoria de toda a cadeia de queijos, incluindo melhoria das raças e do leite, especializando e profissionalizando pequenas e médias empresas, em sua maioria, mobilizadoras de mão de obra familiar na produção e gestão destes empreendimentos.

O objetivo deste trabalho é apresentar uma classificação dos consumidores de queijo através de semânticas de qualidade proferidas em torno de diferenciações e singularidades advindas da relação alimentação-alimento que inferem sobre o gosto relativo ao alimento. Estas semânticas são definidas por variáveis simbólicas, pois conferem significados que ultrapassam a materialidade do alimento (lugar dos ritos alimentares na vida cotidiana, a inserção e importância conferida ao queijo na alimentação, eleição das características nutritivas, funcionais ou demais atributos substanciais ou intrínsecos do queijo no momento da compra e consumo) (singularidades) ou que são elencadas como características objetivas, mensuráveis via preço e passíveis de comparação (diferenciações). Algumas antinonímias entre diferenciação e singularidade serão objeto da análise, no sentido de contribuir com a análise deste mercado de qualidade e seu potencial de desenvolvimento.

O problema de pesquisa é definido pela seguinte indagação: que fundações institucionais de ordem sociocultural nos padrões de consumo do queijo e na alimentação apontam para a constituição de grupos de consumidores e que papel potencial eles têm na estruturação do mercado de qualidade dos queijos que possa se contrapor à concentração da produção pela indústria e à definição dominante da qualidade pelo setor industrial (diferenciações pela variabilidade) e pelo poder público (padrões de conformidade sanitária)?

A hipótese que orienta a reflexão é que persiste uma demarcação em termos de classes econômicas no que diz respeito ao acesso e formas de consumo e inserção do queijo na alimentação, demarcação esta estabelecida através das características diferenciadoras deste alimento. Entretanto, a clássica demarcação em termos de classes econômicas quanto ao acesso, compra e consumo do produto (pirâmide social) não é encontrada através de semânticas de qualidade proferidas pelo conjunto dos consumidores às características do produto enquanto singularidades. Estas singularidades efetivamente podem orientar expectativas de compra e consumo, mensuradas pelas relações estabelecidas entre alimentação-alimento, ainda que estas semânticas tenham expressão e conteúdo variáveis. Em síntese, há demandas de qualidade que não obedecem à hierarquia social ditada pela renda, indicando um grande potencial de consumo dos queijos artesanais junto à população, demanda potencial esta capaz de desafiar a estratégia industrial de concentração da produção, em pequena escala, de queijos finos.

O trabalho está organizado da seguinte maneira: na primeira parte, serão apresentados os conceitos de substância e forma como correspondentes à diferenciação e singularidade como atributos do produto, respectivamente, intrínsecos mercadológicos e extrínsecos inerentes à relação alimentação-alimento; na segunda parte, 
reflexões sobre a distinção entre estratégias de segmentação/subsegmentação industrial e nichos de consumo. Em seguida, a metodologia adotada na investigação e no tratamento dos dados, com apresentação dos resultados classificatórios dos grupos de consumidores e análise. Na conclusão, considerações acerca da importância relativa do capital econômico dos consumidores sobre os padrões de consumo do queijo e sua implicação no potencial desenvolvimento do mercado de qualidade do queijo.

\section{Fundamentação Teórica}

\subsection{Qualidade: consumo e mercados}

O consumo não é apenas uma ação que pretende a satisfação das necessidades imediatas e passíveis de objetivação permanente através dos atributos dos produtos; é uma experiência sensorial, identitária e política, mediada por símbolos, sociabilidades e relações de poder (BARBOSA e CAMPBELL, 2007). A definição do que é a qualidade dos produtos em um mercado depende da produção de dispositivos legitimadores formais em torno dos atributos dos produtos que determinam as concepções da qualidade etiquetáveis a serem publicizadas como diferenciadas. Os consumidores, em suas práticas, podem aderir ou subverter estes dispositivos através de escolhas que lhe são próprias, constitutivas de dispositivos informais, singulares. Padrões de consumo da qualidade são expressões de outras esferas da vida social e não visam apenas a satisfação de expectativas materiais, mas também aquelas simbólicas, subjetivas.

As expectativas simbólicas podem ser de ordem coletiva, atendidas por normas técnicas de qualidade (produtos diferenciados) e referentes apenas à variabilidade do alimento. Elas podem, entretanto, ser mais individualizadas (produtos singulares) e definidas a partir das relações estabelecidas entre alimento-alimentação, tipificando o alimento em um contexto cultural que escapa dos pressupostos unicamente econômicos do mercado. Bourdieu (2006) vai precisar a diferença entre estas esferas - alimento e alimentação - ao afirmar que não se pode autonomizar os consumos alimenta- res - principalmente quando se observa apenas os produtos consumidos e sua qualidade - dos estilos de vida. O gosto, no que diz respeito à alimentação, indetermina-se quando observado apenas no que se refere apenas ao alimento. A comparação sistemática entre as maneiras de tratar a alimentação, de oferecer, servir ou apresentar o alimento, é infinitamente mais reveladora do que a própria natureza do produto em questão, isto é, são mais reveladoras do que as diferenças de qualidade substantivas ou intrínsecas do alimento. No gosto, desta maneira, há o que é, respectivamente, da forma e há o que é da substância.

A distinção entre substância e forma possibilita uma profícua equivalência analítica com a distinção entre, respectivamente, diferenciação e singularidade na sociologia econômica. Nesta subárea de conhecimento, a qualidade é a expressão de normas, regras e parâmetros que se produzem e se incorporam na dinâmica das trocas econômicas e que são traduzidos como valores incorporados aos produtos. Justamente por isso, se tornam únicos, exclusivos. A qualidade pela diferenciação é a qualidade dos bens que resulta do julgamento dos consumidores que confrontam diferentes ofertas disponíveis que se antecipam ao consumo, no sentido em que respondem à necessidade do mercado em proteger-se da concorrência. O preço é o instrumento geral de medida originário de uma mesma hierarquização das características mensuráveis do produto, reconhecida e compartilhada por todos os consumidores (EYMARD-DUVERNAY, 1989). A qualidade pela singularidade não está associada unicamente à função de um produto ou serviço e à sua aptidão em satisfazer as necessidades expressas dos consumidores. A dimensão qualitativa dos produtos advém do espaço das relações sociais e a dimensão do julgamento e da informação sobre a qualidade é mais crítica, uma vez que os produtos são considerados como portadores de um conjunto de configurações incomensuráveis. As singularidades decorrem de uma pluralidade de orientações e de uma pluralidade de atributos de produtos não divisíveis e não combináveis, isto é, que não redutíveis a uma cesta comparável com outras cestas 
através de classificações objetivas e contáveis. Isto é, são universos de significações particulares, objetos de contínuas classificações (KARPIC, 2007). As singularidades são representações sociais do gosto, categoria anterior à preferência, conforme concebida na teoria econômica a qual concebe a escolha do consumidor pela qualidade dentro de regras de equivalência das diferenciações dos produtos ofertados, tendo como pressuposto o equilíbrio geral (CHALITA, 2008).

A qualidade dos queijos pela sua diferenciação diz respeito aos diferentes matizes físico-químicos, aos distintos fluxos de produção em que convergem padrões tecnológicos de produção e às origens particulares das matérias primas, no caso, essencialmente, o total de sólidos presentes no leite, de acordo com a raça do animal e sua alimentação. Estas características são consideradas intrínsecas (ou endógenas) aos queijos (substância do alimento). A qualidade dos queijos, pensada pelo prisma das singularidades do alimento, diz respeito às capacidades e habilidades sociais e cognitivas dos produtores em atentar para as expectativas de satisfação do consumidor, cujas características muitas vezes não dizem respeito apenas aos atributos intrínsecos aos produtos, como é o caso de hábitos alimentares, opções relativas aos cuidados com a saúde, práticas culinárias, ritos alimentares, cerimonialização e significados do compartilhamento familiar e social em torno das refeições, estilos de vida e ideologias alimentares, ética ambiental, religiosa ou social. Até mesmo o consumo de bens culturais em geral, que vão compor o capital cultural e intelectual dos comensais, como por exemplo seus interesses pela gastronomia e pela história da alimentação, pela origem geográfica ou procedência dos alimentos, pelo turismo, seus investimentos em sensibilidades estéticas, aestésicas ${ }^{4} \mathrm{e}$ afetivas, podem determinar a escolha, compra e consumo efetivo do alimento (forma do alimento). $\mathrm{O}$ alimento é portador de significados que traduzem o que se é através do que se come, em termos de identidade, status, prestígio e distinção social, o mundo ao qual se pertence ou se

4 Relativas às propriedades de recepção multissensoriais através de mecanismos de complexa interação simbólica. quer pertencer. Como afirma Fischler (1990), os indivíduos se apropriam do alimento que fará parte de sua intimidade, de seu corpo e de sua imagem através de mecanismos sensoriais particulares, além daquelas características das quais o alimento é portador e que podem ser identificadas por outros diferentes processos formais de validação social e política. Neste sentido, as singularidades são características extrínsecas ao produto e ampliam o leque das gêneses das escolhas alimentares. $\mathrm{Na}$ atualidade, um dos grandes desafios do mercados agroalimentar é fazer com que características extrínsecas sejam cada vez mais materializadas com características intrínsecas.

A incorporação das singularidades como dimensão da qualidade dos produtos vai depender de investimentos na coordenação do mercado que possam garantir a manutenção da diferenciação já existente, o surgimento de outros atributos diferenciadores e a produção das singularidades, como processo ancorado em modos de vida, formas de produção e modalidades de consumo. Em outras palavras, as instituições formais e informais manifestam-se e interpenetram-se, de maneira não pacífica, nos agenciamentos observáveis em um determinado mercado. A forma como se dá a coordenação no mercado (o perfil dos agentes que a integram, seus papéis, relações de poder e hierarquias internas e os mecanismos políticos de decisão e implementação) é que vai definir a qualidade como referência no mercado. Quando há redução da incerteza e mais confiabilidade e reciprocidade, se estabelece maior personalização das trocas econômicas e garantia no estabelecimento de uma relativa homologia entre produção e consumo, um equilíbrio, ainda que instável, entre quantidades demandadas e ofertadas, entre escala e raridade.

A introdução da problemática do consumo na análise dos mercados de qualidade supõe considerar a diferenciação social e os dissensos resultantes em torno do que vem ser a qualidade dentre consumidores e a maneira como a qualidade é formalizada hegemonicamente nas trocas econômicas. Os mercados podem ser analisados em sua estruturação e funcionamento através de 
variáveis socioculturais que tanto definem a demanda real ao incidir nas trocas econômicas vigentes, como também a demanda potencial que pode agir favoravelmente na ampliação da acessibilidade aos produtos de qualidade e no desenvolvimento destes próprios mercados através da própria redefinição do que vem a ser a qualidade.

\subsection{Reflexões sobre a produção e consumo da qualidade nos mercados: segmentação industrial e nichos de consumo}

A relação entre escala de produção e manutenção da raridade do produto, a relação entre a acessibilidade à qualidade e as estratégias de segmentação industrial ou nichos de consumo é central na reflexão sobre o vínculo entre padrões de consumo oriundos da relação alimentação-alimento e a atual estrutura de produção da qualidade do mercado queijeiro. Isto porque neste mercado, a indústria define a qualidade pela $d i$ ferenciação (atributos intrínsecos ao produto) na oferta de variabilidade do alimento. Entretanto, esta variabilidade é efêmera e as características gerais do alimento tendem a se padronizar, em detrimento da definição da qualidade pela singularidade (atributos extrínsecos), definição mais condizente com tipicidade.

A economia industrial tem como objeto de análise a estrutura dos mercados em contextos de concorrência imperfeita, economias de escala/ escopo e diferenciação de produtos que agem na formação de preços em mercados oligopolizados, como é o caso da indústria queijeira no Brasil (REZENDE, 2004). Para Ferraz et al. (1997), uma das estratégias empresariais utilizadas para garantir a competitividade de uma determinada empresa é a manutenção de um espaço privilegiado no mercado, proporcionando maior volume de vendas, maior preço pelo produto e garantias de vendas no médio e longo prazos pela via da diferenciação do produto, uma vez que ela produz barreiras à entrada de competidores. Portanto, preço e diferenciação são fatores que positivizam a competitividade. Isto se aplica bem na estratégia industrial de produção de queijos espe- ciais ou finos via segmentação do mercado em que a qualidade é definida pela utilização de nomes genéricos aos tipos do produto e pelo atendimento aos padrões de conformidade sanitários.

Hoff, Bruch e Pedrozo (2007) afirmam que grandes empresas interessam-se até o nível do segmento de mercado, raramente até o nicho, pois entendem que este último não é lucrativo. A identificação de demandas de consumo mais específicas impõem esforços de precisão de alvo, elevando seus custos fixos. Quando empresas adotam a subsegmentação visando um nicho de mercado, as necessidades dos consumidores-alvos devem ser muito conhecidas para que, apesar do pequeno tamanho do nicho, este se torne altamente rentável. Ou seja, a especialização do produto requer um consumidor que esteja disposto a pagar um preço maior para ter acesso àquele produto. A inespecificidade da inserção do queijo na alimentação do brasileiro (complemento alimentar e/ou consumo em ocasiões especiais) contribui para que a diferenciação industrial se estabeleça segundo a estratégia de segmentação para queijos comuns e a subsegmentação para queijos finos, estes últimos nichos definidos pelo poder de compra dos consumidores. Este padrão competitivo acaba, entretanto, atraindo vários e grandes competidores, resultando em estreitas margens de diferenciação do produto, isto é, incorrendo em relativa padronização dos queijos finos, atendendo a demandas de qualidade de maneira horizontal.

Somadas a estas estratégias de competitividade da indústria queijeira, como a maior parte da produção de leite informal é destinada à industria queijeira, marginalizando as singularidades do alimento na sua forma artesanal, de pequena escala de produção, pequenos e médios produtores não constituem uma ameaça à qualidade legitimada formalmente pela indústria. A utilização de denominações locais e regionais de queijos artesanais pela indústria colabora igualmente para o confinamento da produção artesanal em redes de distribuição informal - ou localizadas ou mais estendidas - ou à comercialização junto a clientelas específicas ou a profissionais da área de gastronomia.

A coerência do uso de estratégia de nicho por empresas de pequeno e médio porte, diante das 
agressivas estratégias de subsegmentação industrial, pode ser mais adequada principalmente por dois motivos: a) estas empresas têm dificuldades de competir em custos com grandes empresas em razão das economias de escala, e a oferta de produtos diferenciados permite-lhes sair da competição por preço; b) em razão do menor porte destas empresas, elas têm mais facilidade para criar produtos altamente especializados com o objetivo de atender uma tendência crescente entre os consumidores: a demanda por produtos customizados ou feitos sob encomenda.

Entretanto, a detecção de nichos de mercado menores e rentáveis, através da identificação de consumidores com características semelhantes e mais exigentes, dificilmente terá alcance globalizado se produtores artesanais atuarem de forma individual e sem ampliação da escala de produção, diante das agressivas estratégias de subsegmentação industrial que pretendem responder às demandas de nicho a partir de uma concepção horizontal do que vem a ser a qualidade no mercado. A adoção de estratégia de nicho pela produção artesanal demanda uma combinação entre diferenciação - singularidades não confundíveis com a diferenciação industrial - e custos. Esta combinação representa uma equação complexa diante da projeção de baixa demanda. Um único mercado-alvo pode ameaçar a sobrevivência da empresa.

$\mathrm{O}$ alimento como portador de cultura e de valores singulares é fundamental nesta reflexão sobre a qualidade. Barjolle e Sylvander (2002) retraçam a origem da ideia de diferenciação para distinguir produtos com qualidade ou características distintas dos produtos standards. Correspondendo à especificidade, a ideia de eficiência econômica, originária da economia industrial, busca definir características específicas mensuráveis no sentido de serem substanciais ou intrínsecas e na condição de o consumidor identificá-las como tal, passíveis de serem substituídas por outras equivalentes. Seu pressuposto é que as firmas operam no mesmo mercado e com os mesmos produtos, e o preço traduz o grau no qual o livre mercado aloca recursos da melhor forma possível para alcançar determinados objetivos em torno da redução de custos, para garantir margens de lucro definidas e para coordenar a produção e as vendas consoantes com os desejos do consumidor para assegurar o bem-estar social.

Alguns países adotaram políticas de qualidade dos produtos agroalimentares que expressam o princípio da diferenciação dos produtos sobre modos específicos de produção, meios geográficos distintos (fatores humanos e naturais) ou até mesmo sobre atributos específicos que asseguram a reputação do alimento junto aos consumidores. Isto é, mais do que uma diferenciação "horizontal", elas criam, legalmente, barreiras à concorrência para produtos artesanais e regionais. Estas iniciativas demonstraram que, do ponto de vista teórico, a noção de eficiência econômica foi contraposta à noção de efetividade econômica. A efetividade econômica diz respeito a uma gama de objetivos possíveis para diferentes produtos e mercados; porém, depende do poder público para a garantia da relação competitiva entre custos e preços para a geração de uma renda de qualidade que suporte as estratégias de nicho pretendidas pela produção artesanal.

Esta tem sido a tendência dos esforços favoráveis à proteção da biodiversidade alimentar: a preservação da autonomia de validação e inserção do alimento artesanal e de origem através de lógicas de ação baseadas em um sistema coerente de valores culturais tradicionais de proximidade. Valores estes que são capazes de alargar seus mercados e sua adaptação a novos contextos institucionais por intermédio da negociação de distintas condições de entrada e permanência. Dentre estas condições, a demonstração que a saúde pública não está em risco é apenas mais uma. Para contrapor-se à lógica da produção de massa criada por parte das grandes corporações transnacionais agroalimentares que levantam barreiras à entrada da produção artesanal de alimento diante de um contexto de políticas menos intervencionistas por parte do Estado e de globalização dos mercados, os movimentos sociais e dos consumidores têm papel central (WILKINSON, 2002, 2010). Abramovay (2000) justifica o alcance da legitimidade destas iniciativas em termos de seu componente territorial nos processos de criação de novos 
recursos como "meios inovadores". O passado dos territórios, sua organização, seus comportamentos coletivos e o consenso que os estrutura são componentes maiores da inovação; os comportamentos inovadores não são nacionais, mas dependem de variáveis definidas ao nível local ou regional, não em termos de atributos naturais ou de localização, mas sim em termos de sua densidade de seu tecido institucional, seu "capital de relações".

\section{Metodologia da pesquisa para a classificação de grupos de consumidores de queijo por classes econômicas}

A pesquisa de campo teve como objetivo classificar grupos de consumidores de queijo e, desta maneira, detectar diferenciações e singularidades expressas ou latentes quanto aos atributos do alimento e à relação alimentação-alimento, por meio da caracterização e dimensionamento social do potencial de demanda de qualidade do alimento. Foi aplicado questionário fechado, com algumas poucas questões em aberto, em locais estratégicos de venda na cidade de São Paulo (Mercado Municipal de São Paulo, o Mercado Municipal da Lapa e o Mercado Municipal de Santo Amaro), cidade que é a maior consumidora de queijos, distante dos locais de produção dos queijos artesanais, junto a consumidores no momento da compra, além de redes sociais ampliadas.

Após a consolidação do banco de dados pelo aplicativo ACESS, o método de tratamentos dos dados foi a análise multivariada (SPSS 15.0). Sobre o banco de dados, foram elaborados Mapas Perceptuais pelo Escalonamento Multidimensional (EMD). O EMD é uma técnica estatística multivariada independente, utilizada para investigar as relações estabelecidas entre variáveis independentes e as múltiplas influências entre si, tendo como variável dependente Classe Econômica ${ }^{5}$ : A técnica do EMD resulta em um conjunto de medi-

5 Os consumidores foram classificados por classe econômica segundo critérios da Abep (Associação Brasileira de Empresas de Pesquisa, 2008) que utiliza como base de dados a POF/FIBGE. das de distâncias entre as variáveis que compõem clusters (nuvens de dados) e de distâncias entre clusters, em um espaço cartesiano arbitrário. Para os dados, não há regras de mensuração, o que torna a técnica muito conveniente para tratar dados provenientes de medidas diferentes, mas que guardem uma lógica entre si. Desse modo, o EMD é usado como técnica de redução de dados, pois permite que se localizem grupos ou conglomerados entre as variáveis ou grupos homogêneos de dados (HAIR et al., 2009). A análise dos resultados observou as variáveis que compõem os clusters, a posição relativa das variáveis internas a eles e aquelas isoladas ou distantes, fora dos clusters, detectando nuances (tendências). Os mapas perceptuais foram precedidos pelo cálculo da média percentual das respostas segundo cada grau da escala Likert (cinco graus) ${ }^{6}$, histogramas de frequência e média das escalas de todas as respostas por variável, segundo cada classe econômica. O resultado obtido foi a qualificação e classificação do perfil de grupos de consumidores em Categorias Analíticas por mapa e, em seguida, uma classificação geral sintética dos mesmos.

Foram definidos dois recortes analíticos nas variáveis investigadas que determinam semânticas de qualidade. O primeiro recorte, composto por variáveis simbólicas em torno dos ritos em relação à alimentação (cerimonialização e sociabilidade), inserção do queijo na alimentação, atributos eleitos do produto no ato da compra (GRUPO I). O segundo recorte, composto por variáveis simbólicas em torno do status, prestígio e diferenciação sociais quanto ao consumo de queijo, ritos em relação à alimentação (cerimonialização e sociabilidade) e nas formas praticadas (comer dentro-fora do ambiente doméstico, compartilhamento da atividade culinária, interesse e acesso a fontes de informação sobre culinária/gastronomia, frequência em eventos de gastronomia regional) e consumo de bens indústria cultural (capital intelectual) (GRUPO II).

\footnotetext{
6 Duas escalas Liekert de 5 graus compuseram o questionário. A primeira composta pelos graus: MI muito importante; I Importante; Ind Indiferente; PI Pouco Importante $\boldsymbol{e}$ NI Nada Importante. A segunda composta pelos graus: DT Discorda Totalmente; DP Discorda Parcialmente; NCND Não concorda Nem Discorda; CP Concorda Parcialmente $\boldsymbol{e}$ CT Concorda Totalmente.
} 


\section{Resultados e análise da classificação dos consumidores de queijo pela relação entre alimento-alimentação}

Clusters de Grupos de Consumidores I: Classes econômicas versus Ritos em relação à alimentação, inserção do queijo na alimentação e atributos eleitos do produto no ato da compra

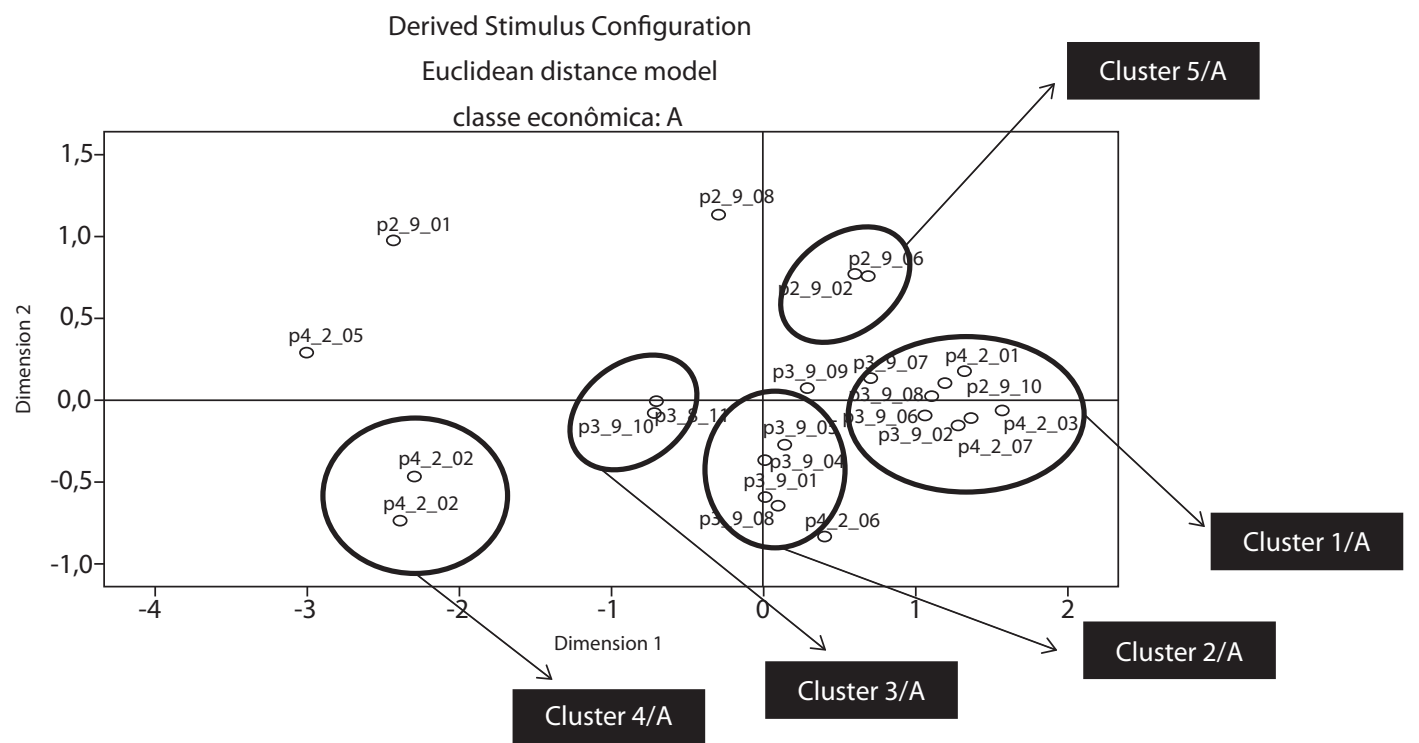

\begin{tabular}{|c|c|c|}
\hline \multicolumn{3}{|c|}{ Classe A } \\
\hline $\begin{array}{l}\text { Associação próxima entre ritos alimentares, cerimonialização } \\
\text { e importância da sociabilidade nas refeições. Incorporação } \\
\text { do queijo nos pratos das refeições principais/ Prazer no } \\
\text { consumo de queijo. Atributos apresentação/embalagem e } \\
\text { higiene/aspectos sanitários (qualidade acessada pela renda) }\end{array}$ & 1 & $\begin{array}{l}\text { 2.9.10. Adoro pratos que vão queijo (CT 74,3\%) } \\
\text { 3.9.02 Higiene e aspectos sanitários (MI } 89,2 \% \text { ) } \\
\text { 3.9.06 Apresentação/Aspecto da embalagem (MI } 67,6 \% \text { ) } \\
\text { 3.9.07 Uso que vai dar ao queijo (MI } 50,0 \% \text { ) } \\
\text { 3.9.08 Prazer pessoal em comer o queijo (MI } 68,9 \% \text { ) } \\
\text { 4.2.01 Gosto de uma mesa bem arrumada quando tenho companhia } \\
\text { para comer (CT 71,6\%) } \\
\text { 4.2.03 As refeições à mesa são ótimas oportunidades de encontro } \\
\text { entre familiares ou amigos (CT } 94,6 \% \text { ) }\end{array}$ \\
\hline $\begin{array}{l}\text { Atributos eleitos na opção de compra e consumo, saúde (teor de } \\
\text { gordura), aspectos nutricionais, marca e preço. Maior proximidade } \\
\text { entre variáveis e atributos do produto em relação às Classes B e C, } \\
\text { preço incluído, no momento da compra. }\end{array}$ & 2 & $\begin{array}{l}\text { 3.9.01 Composição do queijo, os aspectos nutricionais (MI 39,2\%) } \\
\text { 3.9.04. Preço (I 37,8\%) } \\
\text { 3.9.05. Marca (I 44,6\%) } \\
\text { 3.9.03 Teor de gordura (MI 33,8\%) }\end{array}$ \\
\hline $\begin{array}{l}\text { Atributos pouco valorizados na opção de compra e consumo } \\
\text { em relação à Classe B e C }\end{array}$ & 3 & $\begin{array}{l}\text { 3.9.10 Região onde o queijo foi produzido (Ind } 35,1 \% \text { ) } \\
\text { 3.9.11 Forma tradicional de produção do queijo (Ind 43,2\%) }\end{array}$ \\
\hline $\begin{array}{l}\text { Cerimonialização, importância das refeições e alta sociabi- } \\
\text { lidade nas refeições, constrangimento menor do que Classe B } \\
\text { (variáveis mais próximas na Classe A do que na Classe B). }\end{array}$ & 4 & $\begin{array}{l}\text { 4.2.02 Mesmo quando tenho companhia, sou muito prático porque não } \\
\text { me preocupo com a forma de servir e de comer (DT 45,9\%) } \\
\text { 4.2.04 Comer é como qualquer outra tarefa do dia (DT 51,4\%) }\end{array}$ \\
\hline $\begin{array}{l}\text { Reconhecimento das particularidades dos tipos de queijo } \\
\text { associadas ao vinho e associação com sobremesa }\end{array}$ & 5 & $\begin{array}{l}\text { 2.9.02. Queijo combina com sobremesa (CT } 51.4 \% \text { ) } \\
\text { 2.9.06 Não importa o queijo que você está comendo quando bebe } \\
\text { vinho (DT } 43,2 \% \text { ) }\end{array}$ \\
\hline $\begin{array}{l}\text { DISTANTES CLASSE A. Sociabilidade, importância das refei- } \\
\text { çôes e inespecificidade no consumo de queijo (complemento } \\
\text { alimentar) em geral. Queijo associado a ocasiões especiais. }\end{array}$ & & $\begin{array}{l}\text { 2.9.01 Queijo sozinho substitui uma refeição (DT 55.4\%) } \\
\text { 2.9.03 Queijo é sempre uma refeição rápida (CT 43,2\%) } \\
\text { 4.2.05 Não gosto de perder tempo nas refeições (DT 62,2\%) }\end{array}$ \\
\hline
\end{tabular}

Classe A: Renda familiar (acima de R\$ 6.564,00); Gênero: feminino (52,7\%), masculino (47,3\%); Faixa etária: 25-30 anos (13,5\%), 30-40 anos (20,3\%), 40-50 anos (24,3\%), 50-60 anos (29,7\%), acima de 60 anos (12,2\%); Escolaridade: Ginásio incompleto/Primário completo (0\%), Colegial incompleto/ Ginásio completo ( $0 \%$ ), Universitário incompleto/Colegial completo (16,2\%), Universitário completo (com ou sem pós-graduação) ( $83,8 \%$ ) (dados da pesquisa). 


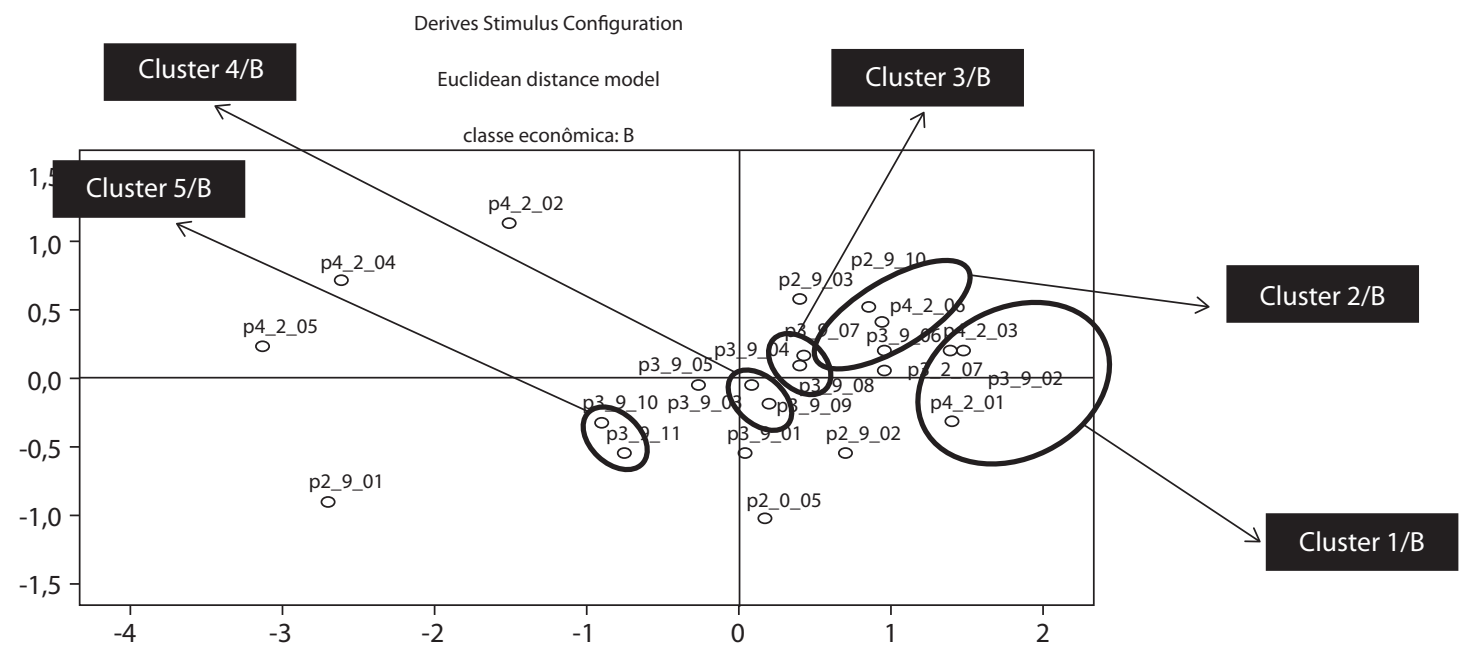

\begin{tabular}{|c|c|c|}
\hline \multicolumn{3}{|c|}{ Classe B } \\
\hline $\begin{array}{l}\text { Menor sociabilidade nas refeições do que Classe A, maior } \\
\text { cerimonialização nas refeições do que Classe A. Destaque } \\
\text { para atributos higiênicos/aspectos sanitários }\end{array}$ & 1 & $\begin{array}{l}\text { 3.9.02 Higiene e aspectos sanitários (MI 85,3\%) } \\
\text { 4.2.01 Gosto de uma mesa bem arrumada quando tenho com- } \\
\text { panhia para comer (CT 75,8\%) } \\
\text { 4.2.03 As refeições à mesa são ótimas oportunidades de encontro } \\
\text { entre familiares ou amigos (CT } 84,2 \% \text { ) } \\
\text { 4.2.07 Comer é sempre muito prazeroso (CT 83,2\%) }\end{array}$ \\
\hline $\begin{array}{l}\text { Destaque Apresentação/Embalagem, uso do queijo } \\
\text { importante como atributo, menor adesão ao queijo do } \\
\text { que Classe A nas refeições principais. Importância das } \\
\text { refeições, mesmo sozinho. }\end{array}$ & 2 & $\begin{array}{l}\text { 3.9.06 Apresentação/Aspecto da embalagem (MI 58,9\%) } \\
\text { 3.9.07. Uso que vai dar ao queijo (MI } 43,2 \% \text { ) } \\
\text { 4.2.06 Mesmo sozinho, as refeições são sagradas para mim (CT 62,1\%) } \\
\text { 2.9.10 Adoro pratos que vão queijo (CT } 67,4 \% \text { ) }\end{array}$ \\
\hline Prazer e uso fortemente associados. & 3 & $\begin{array}{l}\text { 3.9.07 Uso que vai dar ao queijo (MI } 43,2 \% \text { ) } \\
\text { 3.9.08 Prazer pessoal em comer o queijo (MI 57,9\%) }\end{array}$ \\
\hline $\begin{array}{l}\text { Hábito restrito pelo preço do produto. Ausência de } \\
\text { atributos ligados à saúde, aspectos nutricionais. Menor } \\
\text { flexibilidade no consumo de distintos tipos de queijo. }\end{array}$ & 4 & $\begin{array}{l}\text { 3.9.04 Preço (I 49,5\%) } \\
\text { 3.9.09 Hábito familiar ou pessoal do queijo (I 49,5\%) }\end{array}$ \\
\hline $\begin{array}{l}\text { Importância de região dissociada da forma tradicional de } \\
\text { produção em termos de valoração em relação à Classe C, } \\
\text { porém maior proximidade no cluster. }\end{array}$ & 5 & $\begin{array}{l}\text { 3.9.10 Região onde o queijo foi produzido (I } 33,7 \%) \\
\text { 3.9.11 Forma tradicional de produção do queijo (Ind=I 32,6\%) }\end{array}$ \\
\hline $\begin{array}{l}\text { DISTANTES CLASSE B. Sociabilidade, importância } \\
\text { das refeições e queijo como complemento alimentar e } \\
\text { reconhecimento da variedade para ocasiões especiais. }\end{array}$ & & $\begin{array}{l}\text { 2.9.01 Queijo sozinho substitui uma refeição (DT 52,6\%) } \\
\text { 2.9.05 Tem um tipo de queijo para cada ocasião (CT 46,3\%) } \\
\text { 4.2.02 Mesmo quando tenho companhia, sou muito prático } \\
\text { porque não me preocupo com a forma de servir e de comer (DT } \\
\text { 32,6\%). } \\
\text { 4.2.04 Comer é como qualquer outra tarefa do dia (DT } 46,3 \% \text { ) } \\
\text { 4.2.05 Não gosto de perder tempo nas refeições (DT } 54,7 \% \text { ) }\end{array}$ \\
\hline
\end{tabular}

Classe B: Renda familiar (entre R\$ 2.013,00 e R\$ 6.564,00); Gênero: feminino (48,4\%), masculino (51,6\%); Faixa etária: 25-30 anos (20,0\%), 30-40 anos (20,0\%), 40-50 anos (34,7\%), 50-60 anos (19,4\%), acima 60 anos (10,5\%); Escolaridade: Ginásio incompleto/Primário completo (2,1\%), Colegial incompleto/Ginásio completo $(9,5 \%)$, Universitário incompleto/Colegial completo $(40,0 \%)$, Universitário completo (com ou sem pós-graduação) $(48,4 \%)$ (dados da pesquisa). 


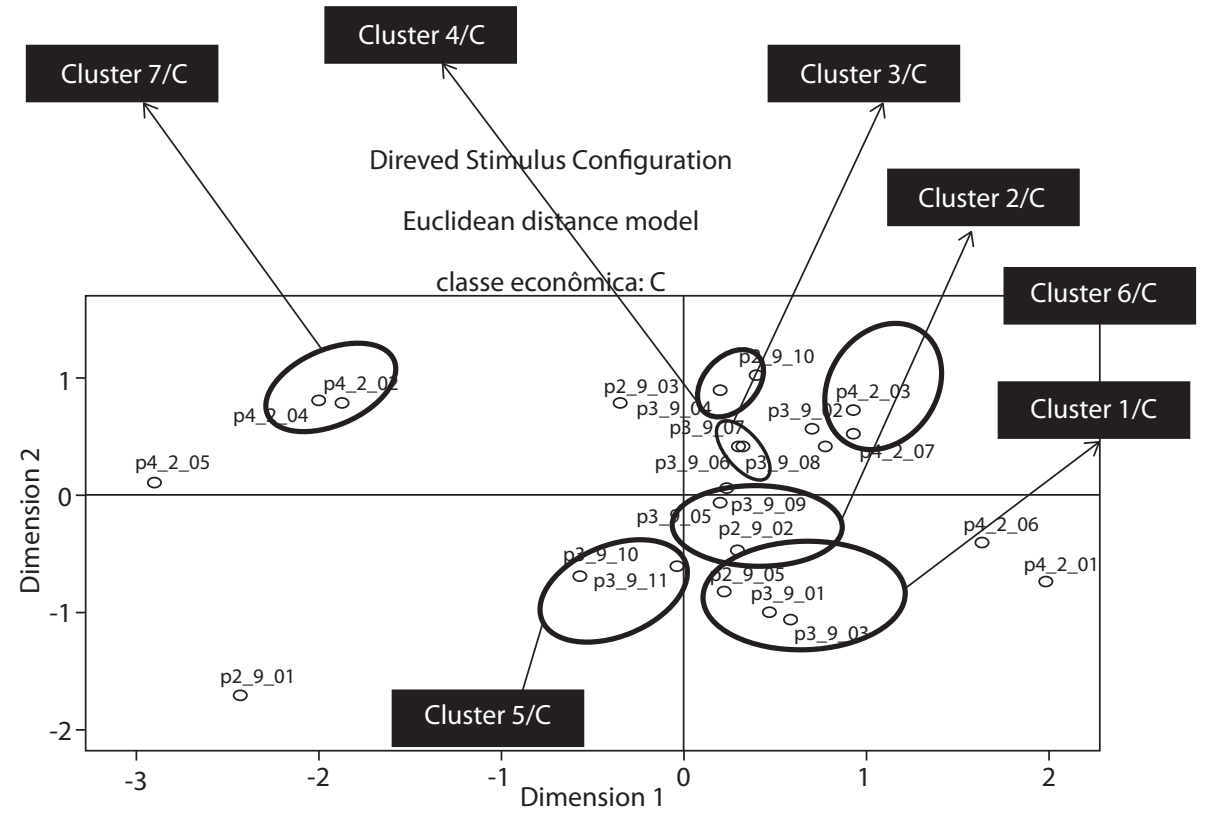

\begin{tabular}{|c|c|c|}
\hline \multicolumn{3}{|c|}{ Classe C } \\
\hline $\begin{array}{l}\text { Atributos relativos à saúde, reconhecimento da variabi- } \\
\text { lidade em ocasióes especiais }\end{array}$ & 1 & $\begin{array}{l}\text { 2.9.05 Tem um tipo de queijo para cada ocasião (CT 50,0\%) } \\
\text { 3.9.01 Composição do queijo, os aspectos nutricionais (MI 27,8\%) } \\
\text { 3.9.02 Higiene e aspectos sanitários (MI 69,4\%) }\end{array}$ \\
\hline $\begin{array}{l}\text { Consumo restrito de tipos de queijo, marca, hábito } \\
\text { familiar ou pessoal }\end{array}$ & 2 & $\begin{array}{l}\text { 2.9.02 Queijo combina com sobremesa (CT 50,0\%) } \\
\text { 3.9.05 Marca (MI 41,7\%) } \\
\text { 3.9.06. Apresentação/aspecto da embalagem (MI 58,3\%) } \\
\text { 3.9.09 Hábito familiar ou pessoal do queijo (MI 44,4\%) } \\
\end{array}$ \\
\hline $\begin{array}{l}\text { Prazer no consumo de queijo restrito pelo preço (preço } \\
\text { mais importante na Classe C do que nas Classes B e A) }\end{array}$ & 3 & $\begin{array}{l}\text { 3.9.04 Preço (MI } 69,4 \% \text { ) } \\
\text { 2.9.10. Adoro pratos que vão queijo ( (CT } 72,2 \% \text { ) }\end{array}$ \\
\hline Uso e prazer associados & 4 & \begin{tabular}{|l} 
3.9.07 Uso que vai dar ao queijo (MI $50,0 \%)$ \\
3.9.08 Prazer pessoal em comer o queijo (MI 69,4\%)
\end{tabular} \\
\hline $\begin{array}{l}\text { Importância de região e forma tradicional de produção } \\
\text { mais importante do que Classes B e A, porém mais } \\
\text { distantes do que em B. Menor conhecimento da vincu- } \\
\text { lação entre estes dois atributos. }\end{array}$ & 5 & $\begin{array}{l}\text { 3.9.10 Região onde o queijo foi produzido (Ind=I=MI 25,0\%) } \\
\text { 3.9.11 Forma tradicional de produção do queijo (Ind 33,3\%; I 30,6\%) }\end{array}$ \\
\hline $\begin{array}{l}\text { Sociabilidade menor do que Classes B e A. Prazer nas } \\
\text { refeições. Higiene/aspectos sanitários como atributo. }\end{array}$ & 6 & $\begin{array}{l}\text { 3.9.02. Higiene e aspectos sanitários }(\mathrm{MI} 69,4 \%) \\
\text { 4.2.03. As refeições à mesa são ótimas oportunidades de encontro } \\
\text { entre familiares ou amigos (CT 80,6\%) } \\
\text { 4.2.07 Comer é sempre muito prazeroso (CT 83,3\%) }\end{array}$ \\
\hline $\begin{array}{l}\text { Constrangimento no dia-a-dia e ao mesmo tempo ceri- } \\
\text { monialização no ambiente doméstico }\end{array}$ & 7 & $\begin{array}{l}\text { 4.2.01. Gosto de uma mesa bem arrumada quando tenho com- } \\
\text { panhia para comer(CT 63,9\%) } \\
\text { 4.2.04. Comer é como qualquer outra tarefa do dia (CT } 38,9 \%)\end{array}$ \\
\hline $\begin{array}{l}\text { DISTANTES CLASSE C. Mais constrangimentos no dia- } \\
\text {-a-dia, mas importância da cerimonialização da refeiçãa. } \\
\text { Maior importância ao queijo como substituindo refeição } \\
\text { do que Classes A e B (maior frequência de lanches). }\end{array}$ & & $\begin{array}{l}\text { 2.9.01. Queijo sozinho substitui uma refeição (DT } 41.7 \% \text { ) } \\
\text { 4.2.01. Gosto de uma mesa bem arrumada quando tenho } \\
\text { companhia para comer (CT } 63,9 \% \text { ) } \\
\text { 4.2.05. Não gosto de perder tempo nas refeições (DT } 41,7 \% \text { ) } \\
\text { 4.2.06 Mesmo sozinho, as refeições são sagradas para mim (CT } \\
61,1 \% \text { ) }\end{array}$ \\
\hline
\end{tabular}

Classe C: Renda familiar (entre R \$ 726,00 e R \$ 2.013,00); Gênero: feminino (69,4\%), masculino (30,6\%); Faixa etária: 25-30 anos (11,1\%), 30-40 anos (30,6\%), 40-50 anos (19,4\%), 50-60 anos (19,4\%), acima 60 anos (19,4\%); Escolaridade: Ginásio incompleto/Primário completo (44,4\%), Colegial incompleto/Ginásio completo (25,0\%), Universitário incompleto/Colegial completo (27,8\%), Universitário completo (com ou sem pós-graduação) $(2,8 \%)$ (dados da pesquisa). 


\section{Clusters de Grupos de Consumidores II: Classes econômicas versus Estilos de vida em relação à alimentação}

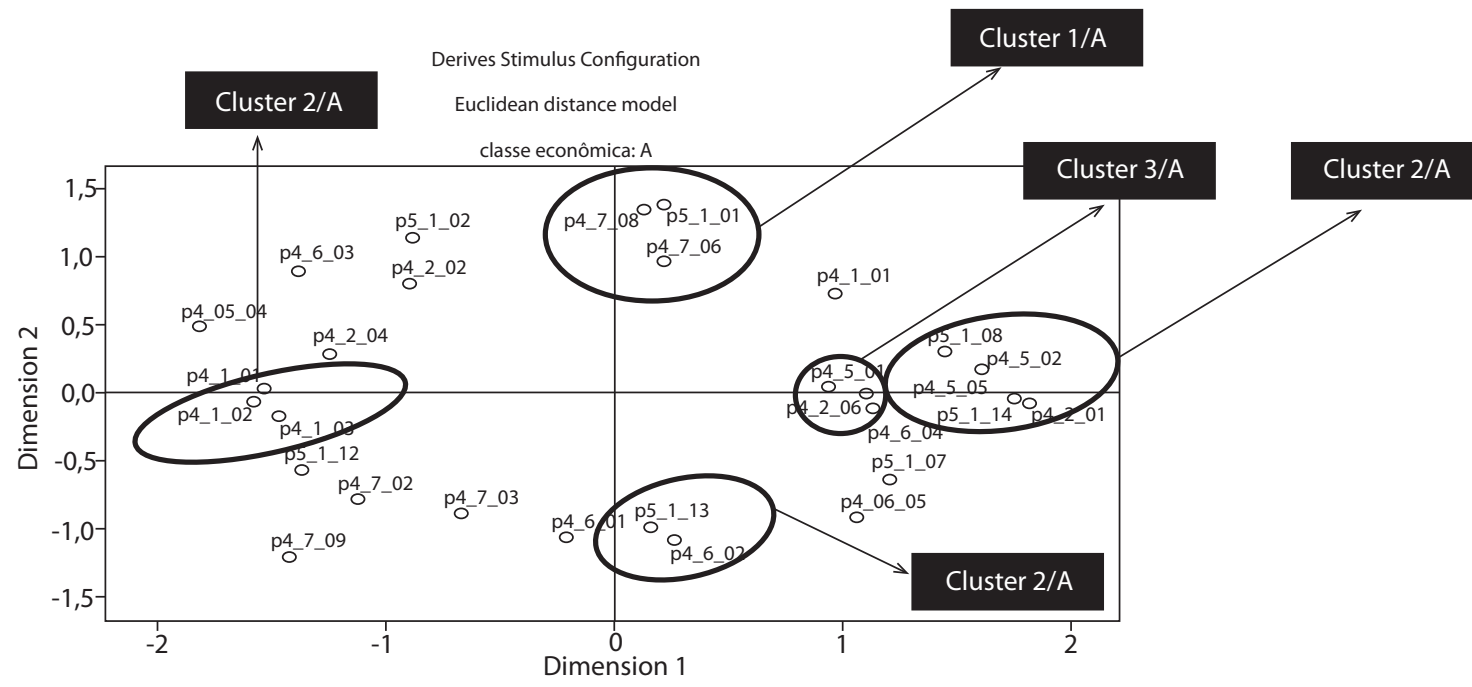

\begin{tabular}{|c|c|c|}
\hline \multicolumn{3}{|c|}{ Classe A } \\
\hline $\begin{array}{l}\text { Oscilação gourmets e constrangimentos: a ritualização das } \\
\text { refeições ocorre fora do ambiente doméstico }\end{array}$ & 1 & $\begin{array}{l}\text { 4.7.06. Faço apenas receitas do dia-a-dia (trivial) (DT=CT 28,4\%) } \\
\text { 4.7.08 Não me preocupo com receitas (CT 29,7\%; DT 28,4\%) } \\
\text { 5.1.01 Sou do tipo caseiro (CT 44,6\%) }\end{array}$ \\
\hline $\begin{array}{l}\text { Restaurantes, refinamento (restaurante para mudar } \\
\text { de ambiente mais importante que praticidade), pratos } \\
\text { regionais quando em viagem }\end{array}$ & 2 & $\begin{array}{l}\text { 4.2.01. Gosto de uma mesa bem arrumada quando tenho } \\
\text { companhia para comer (CT 71,6\%) } \\
\text { 4.5.02. Gosto de comer em restaurantes para variar de ambiente } \\
\text { (CT } 60,8 \% \text { ) } \\
\text { 4.5.05. Gosto de comer em restaurantes para variar a comida (CT } \\
\text { 60,8\%) } \\
\text { 5.1.08. Assisto televisão todos os dias (CT } 67,6 \% \text { ) } \\
\text { 5.1.14. Quando viajo gosto de experimentar a comida típica do } \\
\text { local (CT } 71,6 \% \text { ) }\end{array}$ \\
\hline $\begin{array}{l}\text { Frequência de ida a restaurantes como praticidade, prazer } \\
\text { nas refeições mesmo sozinho }\end{array}$ & 3 & $\begin{array}{l}\text { 4.5.01. Vou a restaurantes porque é mais prático (CT 36,5\%) } \\
\text { 4.2.06. Mesmo sozinho, as refeições são sagradas para mim (CT 52,7\%) }\end{array}$ \\
\hline $\begin{array}{l}\text { Menor interesse no tema culinária ou gastronomia em } \\
\text { relação à Classe B. Pouca frequência a eventos mais } \\
\text { populares em relação à Classe B e C. }\end{array}$ & 4 & $\begin{array}{l}\text { 4.6.02. Gosto de conversar sobre culinária ou gastronomia (CT 32,4\%) } \\
\text { 5.1.13. Gosto de ir a exposiçôes, festas ou eventos em que haja } \\
\text { comidas regionais do Brasil ou de outros países (DT =CT 33,8\%) }\end{array}$ \\
\hline $\begin{array}{l}\text { Não sofisticação e diferenciação no consumo de queijos. } \\
\text { Indiferença quanto ao consumo de queijos artesanais ou } \\
\text { com procedência geográfica }\end{array}$ & 5 & $\begin{array}{l}\text { 4.1.02. Sou sofisticado porque gosto de comer queijo (DT } 67,6 \% \text { ). } \\
\text { 4.1.03. Comer certos tipos de queijos me diferencia das demais } \\
\text { pessoas (DT } 63,5 \% \text { ) } \\
\text { 4.1.04. Sempre procuro comer o queijo produzido na minha terra } \\
\text { (DT } 62,2 \% \text { ) }\end{array}$ \\
\hline $\begin{array}{l}\text { DISTANTES CLASSE A: Privilégio, sociabilidade, prazer } \\
\text { na refeição e prazer em frequentar restaurantes. Pouco } \\
\text { interesse cognitivo na culinária ou gastronomia. }\end{array}$ & & $\begin{array}{l}\text { 4.1.01. Sinto-me privilegiado porque posso comer certos tipos } \\
\text { queijos (CT 51,4\%) } \\
\text { 4.2.02 Mesmo quando tenho companhia, sou muito prático porque } \\
\text { não me preocupo com a forma de servir e de comer (DT } 45,9 \% \text { ) } \\
\text { 4.2.04 Comer é como qualquer outra tarefa do dia (DT } 51,4 \% \text { ) } \\
\text { 4.6.03 Cozinhar é um ato solitário (DT } 58,1 \% \text { ) } \\
\text { 4.6.05 Gosto de cozinhar para amigos ou parentes (CT } 51,4 \% \text { ) } \\
\text { 4.5.04. Só vou a restaurante porque não tenho outra opção (DT } 67,6 \% \text { ) } \\
\text { 4.7.02 Sempre compro livros especializados em culinária (DT } \\
54,1 \% \text {; DP 14,9\%) } \\
\text { 4.7.03 Assisto sempre programas de culinária na televisão (DT } 47,3 \% \text { ) } \\
\text { 4.7.09. Já fiz curso de culinária/gastronomia (DT 70,3\%; CT } 23,0 \% \text { ) } \\
\text { 5.1.02 Dificilmente vou ao cinema (DT } 47,3 \% \text { ) } \\
\text { 5.1.12 Vou sempre a eventos de degustação de bebidas ou pratos } \\
\text { (DT 59,5\%) }\end{array}$ \\
\hline
\end{tabular}




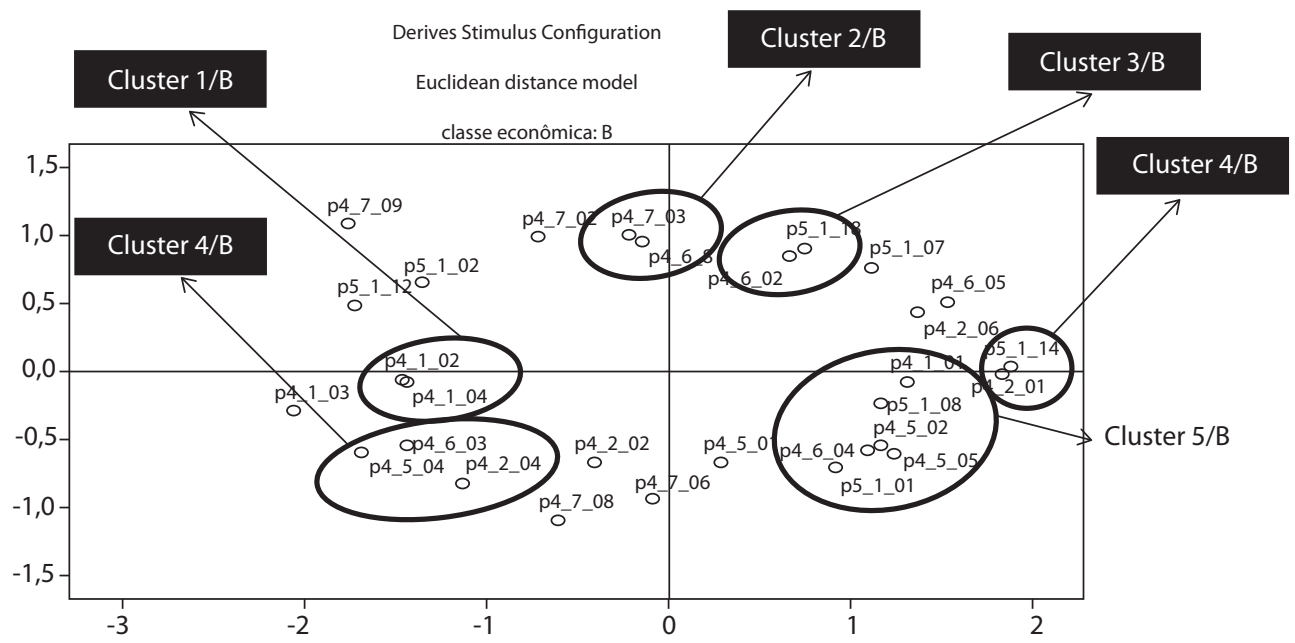

\begin{tabular}{|c|c|c|}
\hline \multicolumn{3}{|c|}{ Classe B } \\
\hline $\begin{array}{l}\text { Sofisticação maior em comer queijo do que Classe A e na } \\
\text { valorização do queijo artesanal ou de origem em relação à } \\
\text { Classe A }\end{array}$ & 1 & $\begin{array}{l}\text { 4.1.02. Sou sofisticado porque gosto de comer queijo (DT } 60,0 \% \text { ). } \\
\text { 4.1.04. Sempre procuro comer o queijo produzido na minha terra } \\
\text { (DT } 52,6 \% \text { ) }\end{array}$ \\
\hline $\begin{array}{l}\text { Maior interesse pela prática culinária do que Classe A. Maior } \\
\text { interesse em programas de culinária do que Classes A e C. }\end{array}$ & 2 & $\begin{array}{l}\text { 4.6.01. Gosto de testar as receitas que experimento em restaurantes } \\
\text { (DT 38,9\%; CT } 24,2 \% \text { ) } \\
\text { 4.7.03. Assisto sempre programas de culinária na televisão (DT 37,9\%) }\end{array}$ \\
\hline $\begin{array}{l}\text { Mais interesse nas variáveis do que Classe A: culinária, } \\
\text { gastronomia. }\end{array}$ & 3 & $\begin{array}{l}\text { 4.6.02. Gosto de conversar sobre culinária ou gastronomia (CT 35,8\%) } \\
\text { 5.1.11. Não tenho muito tempo para ler (DT 32,6\%) }\end{array}$ \\
\hline $\begin{array}{l}\text { Cerimonialização e abertura a pratos regionais em viagem } \\
\text { como Classe A }\end{array}$ & 4 & $\begin{array}{l}\text { 4.2.01. Gosto de uma mesa bem arrumada quando tenho companhia } \\
\text { para comer (CT 75,8\%) } \\
\text { 5.1.14. Quando viajo gosto de experimentar a comida típica do local } \\
\text { (CT 73,7\%) }\end{array}$ \\
\hline $\begin{array}{l}\text { Privilégio, ida ao restaurante mais determinada pela variação } \\
\text { de pratos do que para ambiente (Para a Classe A, ambiente } \\
\text { do restaurante é tem maior frequência). }\end{array}$ & 5 & $\begin{array}{l}\text { 4.1.01 Sinto-me um privilegiado porque posso comer certos tipos de } \\
\text { queijo (CT 58,9\%) } \\
\text { 4.5.02. Gosto de comer em restaurantes para variar de ambiente (CT 47,4\%) } \\
\text { 4.5.05. Gosto de comer em restaurantes para variar a comida (CT 50,5\%) } \\
\text { 4.6.04. Gosto de cozinhar quando tenho companhia na cozinha (CT 48,4\%) } \\
\text { 5.1.01 Sou do tipo caseiro (CT 45,3\%) } \\
\text { 5.1.08. Assisto televisão todos os dias (CT } 54,7 \% \text { ) }\end{array}$ \\
\hline $\begin{array}{l}\text { Associação entre variáveis mostra maior constrangimento } \\
\text { na atividade culinária e na frequência a restaurantes do que } \\
\text { Classe A. }\end{array}$ & 6 & $\begin{array}{l}\text { 4.2.04. Comer é como qualquer outra tarefa do dia (DT 46,3\%) } \\
\text { 4.5.04. Só vou a restaurante porque não tenho outra opção (DT 55,8\%) } \\
\text { 4.6.03. Cozinhar é um ato solitário (DT 51,6\%) }\end{array}$ \\
\hline $\begin{array}{l}\text { DISTANTES CLASSE B: Sociabilidade, prazer na refeição, em } \\
\text { cozinhar e na gastronomia (maior que A). }\end{array}$ & & $\begin{array}{l}\text { 4.1.03. Comer certos tipos de queijos me diferencia das demais pessoas } \\
\text { (DT 72,6\%) } \\
\text { 4.2.02. Mesmo quando tenho companhia, sou muito prático porque } \\
\text { não me preocupo com a forma de servir e de comer DT 32,6\%). } \\
\text { 4.2.06 Mesmo sozinho, as refeições são sagradas para mim (CT } 62,1 \% \text { ) } \\
\text { 4.5.01 Vou a restaurantes porque é mais prático (CP } 34,7 \% \text { ) } \\
\text { 4.6.05. Gosto de cozinhar para amigos ou parentes (CT 2,1\%) } \\
\text { 4.7.02. Sempre compro livros especializados em culinária (DT } 47,4 \% \text { ) } \\
\text { 4.7.06. Faço apenas receitas do dia-a-dia (trivial) (CP } 31,6 \% \text { ) } \\
\text { 4.7.08. Não me preocupo com receitas (DP } 28,4 \% \text { ) } \\
\text { 4.7.09. Já fiz curso de culinária/gastronomia (DT } 74,7 \% \text { ) } \\
\text { 5.1.02. Dificilmente vou ao cinema (DT } 48,4 \% \text { ) } \\
\text { 5.1.07 Sempre encontro um tempinho para ler um livro (CT } 48,4 \% \text { ) } \\
\text { 5.1.12. Vou sempre a eventos de degustação de bebidas ou pratos (DT } \\
\text { 68,4\%) }\end{array}$ \\
\hline
\end{tabular}




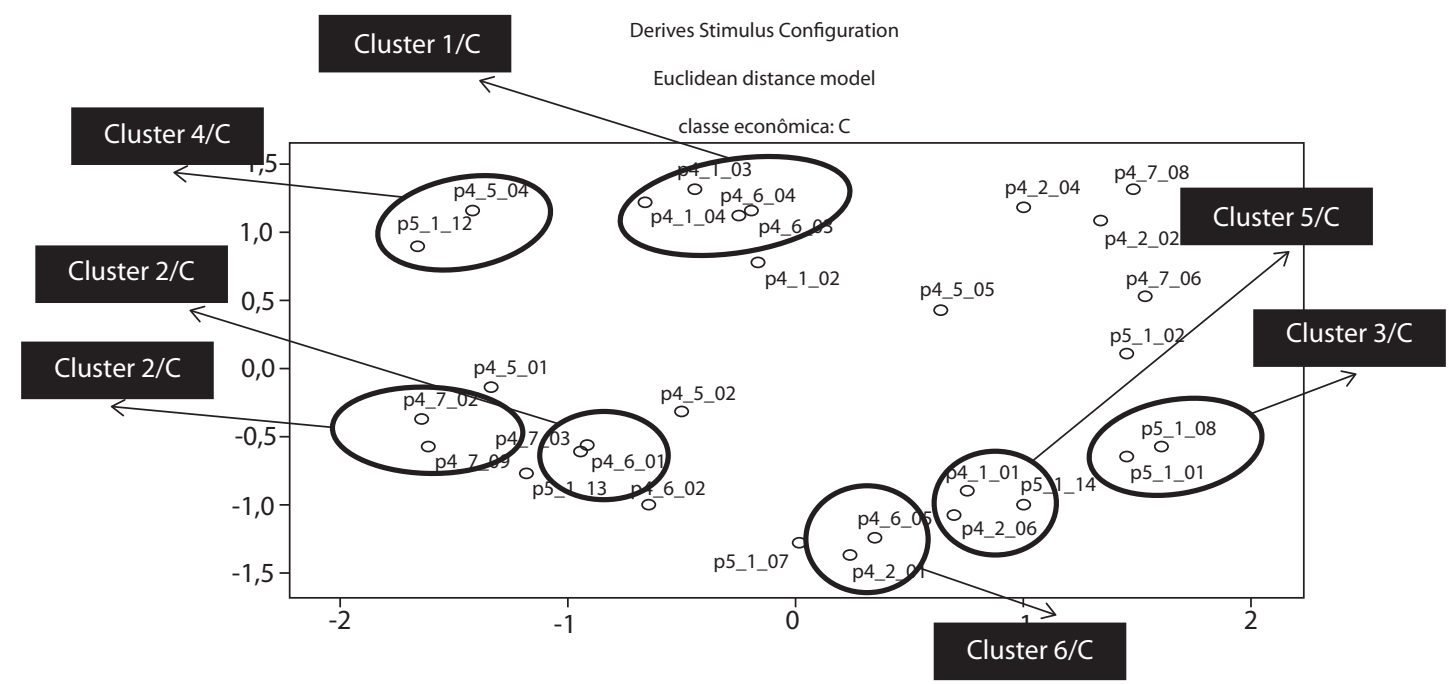

\begin{tabular}{|c|c|c|}
\hline \multicolumn{3}{|c|}{ Classe C } \\
\hline $\begin{array}{l}\text { Cozinhar dissociado de prazer (constrangimento), maior grau } \\
\text { de concordância com "comer queijo da sua terra" em relação } \\
\text { às Classes A e B. }\end{array}$ & 1 & $\begin{array}{l}\text { 4.1.03. Comer certos tipos de queijos me diferencia das demais pessoas } \\
\text { (DT 52,8\%) } \\
\text { 4.1.04 Sempre procuro comer o queijo produzido na minha terra (DT } \\
52,8 \% \text { ) } \\
\text { 4.6.04. Gosto de cozinhar quando tenho companhia na cozinha (DT } \\
44,4 \% \text { ) } \\
\text { 4.6.05. Gosto de cozinhar para amigos ou parentes (CT } 55,6 \% \text { ) }\end{array}$ \\
\hline $\begin{array}{l}\text { Pouco acesso e interesse em culinária ou gastronomia, pouco } \\
\text { interesse em cozinhar pratos novos }\end{array}$ & 2 & $\begin{array}{l}\text { 4.6.01. Gosto de testar as receitas que experimento em restaurantes } \\
\text { (DT 47,2\%; CT 33,3\%) } \\
\text { 4.7.03. Assisto sempre programas de culinária na televisão (DT 41,7\%) } \\
\end{array}$ \\
\hline $\begin{array}{l}\text { Associação e média maior na negativa de acesso aos bens culturais. } \\
\text { Comportamento mais doméstico, menor frequência a eventos culturais. }\end{array}$ & 3 & $\begin{array}{l}\text { 5.1.01. Sou do tipo caseiro (CT } 63,9 \% \text { ) } \\
\text { 5.1.08. Assisto televisão todos os dias (CT 72,2\%) }\end{array}$ \\
\hline $\begin{array}{l}\text { Não frequência a eventos de degustação, prazer em ir a restaurantes } \\
\text { como evento ocasional }\end{array}$ & 4 & $\begin{array}{l}\text { 4.5.04. Só vou a restaurante porque não tenho outra opção (DT 72,2\%) } \\
\text { 5.1.12. Vou sempre a eventos de degustação de bebidas ou pratos (DT } \\
77,8 \% \text { ) }\end{array}$ \\
\hline $\begin{array}{l}\text { Privilégio, interesse por culinária regional menor do que } \\
\text { Classes A e B, prazer na refeição }\end{array}$ & 5 & $\begin{array}{l}\text { 4.1.01. Sinto-me um privilegiado porque posso comer certos tipos } \\
\text { queijos (CT 58,3\%) } \\
5.1 .14 \text {. Quando viajo gosto de experimentar a comida típica do local } \\
\text { (CT } 66,7 \% \text { ) } \\
\text { 4.2.06. Mesmo sozinho, as refeições são sagradas para mim (CT } 61,1 \%)\end{array}$ \\
\hline $\begin{array}{l}\text { Alta sociabilidade e cerimonialização quando recebe. Pouco } \\
\text { destaque no hábito de cozinhar }\end{array}$ & 6 & $\begin{array}{l}\text { 4.2.01. Gosto de uma mesa bem arrumada quando tenho companhia } \\
\text { para comer (CT } 63,9 \% \text { ) } \\
\text { 4.6.06. Cozinhar desperta lembranças agradáveis do passado (DT 41,7\%) }\end{array}$ \\
\hline $\begin{array}{l}\text { Não frequenta cursos e não compra livros especializados em } \\
\text { culinária/gastronomia }\end{array}$ & 7 & $\begin{array}{l}\text { 4.7.02. Sempre compro livros especializados em culinária/gastronomia } \\
\text { (DT 61,1\%) } \\
\text { 4.7.09 Já fiz curso de culinária/gastronomia (DT 63,9\%) }\end{array}$ \\
\hline $\begin{array}{l}\text { DISTANTES CLASSE C: Menor sociabilidade nas refeições, } \\
\text { menos interesse em culinária e gastronomia, menos interesse } \\
\text { em comidas regionais do que Classes A e B }\end{array}$ & & $\begin{array}{l}\text { 4.1.02 Sou sofisticado porque gosto de comer queijo (DT } 36,1 \% \text { ) } \\
\text { 4.2.02. Mesmo quando tenho companhia, sou muito prático porque } \\
\text { não me preocupo com } \\
\text { a forma de servir e de comer (CT } 38,9 \% \text { ) } \\
\text { 4.2.04 Comer é como qualquer outra tarefa do dia (CT } 38,9 \% \text { ) } \\
\text { 4.5.01 Vou a restaurantes porque é mais prático (DT } 55,6 \% \text { ) } \\
\text { 4.5.02. Gosto de comer em restaurantes para variar de ambiente (DT } \\
\text { 36,1\%) } \\
\text { 4.5.05. Gosto de comer em restaurantes para variar a comida (CT 38,9\%) } \\
\text { 4.6.02. Gosto de conversar sobre culinária ou gastronomia (CT } 47,2 \% \text { ) } \\
\text { 4.7.06. Faço apenas receitas do dia-a-dia (trivial) (CT } 41,7 \% \text { ) } \\
\text { 5.1.02 Dificilmente vou ao cinema (CT } 52,8 \% \text { ) } \\
\text { 5.1.07. Sempre encontro um tempinho para ler um livro (CT } 52,8 \% \text { ) }\end{array}$ \\
\hline
\end{tabular}


A classificação final e sintética dos consumidores pode ser observada abaixo:

\begin{tabular}{|l|l|l|}
\hline \multicolumn{3}{|c|}{ Classes econômicas versus Ritos em relação à alimentação, } \\
inserção do queijo na alimentação e atributos eleitos do produto no ato da compra
\end{tabular}

Grupos de consumidores II:

Classes econômicas versus Estilos de vida em relação à alimentação

\section{CLASSE A}

Estilização e sofisticação da Estilização e sofisticação fora e denalimentação fora do ambiente tro do ambiente doméstico, maior doméstico, pouca aderência à aderência à culinária ou gastronomia, culinária ou gastronomia como consumo da culinária regional em prática cotidiana, consumo da viagens e eventos típicos, maior culinária regional em viagens. interesse pelo tema culinária/gasPouco interesse em culinária e tronomia do que Classe A por meio de gastronomia. fontes de informação diversas.

\section{CLASSE C}

Alimentação, ato de cozinhar e inovação no cardápio com constrangimentos, maior distância do prazer gastronômico, pouca frequência a atos alimentares fora do ambiente doméstico; menor frequência a eventos de degustação e consumo de pratos regionais; menor interesse pelo tema culinária/ gastronomia do que Classe B. Cozinha mais trivial.
A partir de uma equivalência analítica entre substância-alimento (diferenciação) e forma-alimentação (singularidade), os resultados apontam para:

1. uma sofisticação nos ritos alimentares da Classe A pelo distanciamento com a ritualização das refeições unicamente no ambiente doméstico e acento na ambientação dos restaurantes, ainda que lhes acorde importância como momento de sociabilidade familiar e social. Cisão na relação alimentação-alimento, resultando em distanciamento das singularidades que cercam esta relação e, ao mesmo tempo, uma irrestrição no consumo da variabilidade do produto, isto é, das diferenciações deste alimento. Expressão de uma desvalorização dos atributos do produto artesanal brasileiro. A ênfase na embalagem e marca testemunha que o consumo ocorre segundo uma sensibilidade cognitiva mais restrita às características substanciais ou intrínsecas (organolépticas) ou à notoriedade do queijo. A maior ênfase na origem do que nas formas tradicionais de produção confirma os padrões de consumo pela reputação do produto;

2. maior frequência de refeições no ambiente doméstico e uso de restaurantes mais associado com praticidade. A Classe B assume uma posição em relação à qualidade do alimento que se aproxima de $\mathrm{A}$, isto é, reconhece sua variabilidade, ainda que restrições financeiras dificultem o acesso cotidiano à diferenciação do produto. A apropriação do queijo nas ocasiões especiais revela a eleição do produto pela sua diferenciação de forma pontual. A Classe $B$ foi a que mais revelou aderência às singularidades da relação alimentação- 
-alimento (maior prazer na prática culinária compartilhada, alta sociabilidade) e das singularidades do produto por meio da aproximação entre as variáveis região e forma tradicional de produção. Em oposição às Classes A e C, a Classe B apresenta diferenças no consumo e na semântica da qualidade segundo seu capital intelectual no que se refere ao interesse pela culinária e gastronomia e fontes de informação, importância dada ao consumo do queijo de "sua terra" e no consumo de bens da indústria cultural, explicitando maior destaque aos valores mobilizados pela produção artesanal. Concordância maior com privilégio e sofisticação em comer queijos e tipos diferenciados do que Classe A, dada a restrição maior no consumo;

3. a importância do consumo de queijo como ingredientes de lanches e o preço do produto explica que prestígio e diferenciação sociais no consumo do produto são atribuídos por esta classe mais que nas Classes B e A. Da mesma forma, a eleição dos atributos que podem ser conferidos à produção artesanal do alimento tem maior média na Classe C. As semânticas de qualidade na Classe $C$ revelam uma aderência identitária entre alimentação e alimento (queijo) (maior sensibilidade a produtos de origem, ainda que menos dissociada do que a Classe B no que diz respeito à forma tradicional de produção, indicando provável desconhecimento da relação entre estas variáveis). Prazer dissociado dos atributos higiênicos e nutricionais do alimento.

A demanda potencial por singularidades foi detectada não apenas pelas características intrínsecas do alimento, mas igualmente pela persistência de processos de identidade-identificação nas semânticas de qualidade proferidas ao se considerar a relação estabelecida entre alimentação-alimento. Nos dois casos, esta demanda foi inversa à da pirâmide social, detectando-se que classes de menor renda não aderem aos produtos massificados:

1. maior realização efetiva da compra do queijo pelos seus atributos de qualidade diferenciada, disponíveis no mercado, de acordo com o capital econômico que as classes detêm, destacando-se a Classe A; porém, gosto e desejo de consumo de atributos singulares mais pronunciados nas Classes B e C;

2. maior associação entre intimidade-sociabilidade no que diz respeito aos ritos alimentares nas classes de menor poder aquisitivo. Pelo perfil de escolaridade das Classes A, B e C, conclui-se igualmente que esta relação traduz forte afetividade e interesse cultural, independentemente do grau de instrução.

\section{Conclusão}

A partir das semânticas da qualidade proferidas, observou-se um distanciamento entre alimentação e alimento nas classes de maior renda e sua aproximação nas classes de menor renda, além da valorização que estas últimas fazem das características intrínsecas do produto artesanal. O perfil econômico do consumidor responde pelo consumo efetivo do produto em suas diferenciações, mas a alimentação tira a posição de causalidade qualidade-preço quando a relação alimento-alimentação é considerada como sociabilidade, compartilhamento, cognição, pertencimento social, afetividade, intimidade e identidade. Estas esferas expressam, com distintos graus, a produção sociocultural da qualidade do alimento em suas singularidades no contexto alimentar para além do cardápio de produtos disponibilizados atualmente pela indústria. As semânticas da qualidade encontradas indicam, desta maneira, tensões entre a produção e o consumo quanto às instituições de qualidade do produto.

O "território" construído institucionalmente através de políticas públicas tem avançado na valorização dos produtos artesanais e de origem 
pelos aspectos culturais envolvidos. Entretanto, o foco em nichos de consumo de renda elevada e em circuitos de comercialização específicos e de excelência tem instáveis impactos positivos na valorização desta produção. Inovações tecnológicas que permitam aumentar a escala de produção, individualmente ou de forma associativa, e incorporar regras e normas técnicas sanitárias, sem comprometer os valores institucionais, técnicos e simbólicos do alimento artesanal e de origem, devem ser consideradas como imprescindíveis. Iniciativas de valorização deste alimento, ainda que incipientes, conflitam com a abrangência do significado do consumo como apropriação, manipulação e ressignificação do mundo material, capaz de impor resistência à tendência de padronização e à impessoalidade e despersonalização do alimento determinadas pelo sistema agroalimentar, e capaz de legitimar, inclusive, novas justificativas favoráveis ao desenvolvimento local e regional por meio de uma posição favorável ao acesso e consumo estendidos do alimento pela população.

A democratização do consumo da qualidade e a superação do viés agrário responsável, em muito, pela constante reificação do modo de produção familiar nas políticas públicas, podem dar maior visibilidade aos atributos singulares dos produtos tipicamente nacionais, melhorando a imagem pejorativa do produto artesanal, como rudimentar e de qualidade duvidosa e, consequentemente, tornar-se uma sólida alternativa para desconcentrar a formulação dos dispositivos formais de qualidade pela indústria e projetar o País no mercado internacional com alimentos tipicamente nacionais. Dados de Filho e Campos (2003) atestam que a indústria artesanal de queijos e requeijão no Brasil ocupa, em termos de volume de produção e em termos de valor das receitas, a segunda posição dentre os produtos artesanais.

No caso do queijo, esta democratização da qualidade dos valores embutidos nos tipos artesanais do produto não depende apenas da valorização institucional dos territórios e das estruturas familiares de sua produção, nos mesmos moldes do analisado por Anjos et al. (2011), mas sim a constituição de uma rede institucional capaz de impor-se aos padrões de concorrência da indústria queijeira, visto ser o queijo (contrariamente ao vinho) um alimento ainda bastante inespecífico no consumo alimentar e a visibilidade das singularidades dos tipos brasileiros artesanais em grandes centros urbanos ser ainda muito incipiente.

\section{Referências bibliográficas}

ABRAMOVAY, R. "O capital social dos territórios: repensando o desenvolvimento rural" Economia Aplicada, v. IV, n. 2, pp. 379-397, abr-jun.2000.

ANJOS, F. S. dos; CRIADO, E. A. e CALDAS, N. V. "Estratégias de valorización de productos locales em Espana Y Brasi"1. Revista de Economia Agrícola, v. 58, n. 1, jan-jun.2011.

BARBOSA, L. e CAMPBELL, C. (Orgs). Cultura $e$ Identidade. FGV Editora. 2007.

BARJOLLE, D. e SYLVANDER, B. "Some factors for Origin Labelled Products in Agro-Food Supply Chains in Europe: market, internal resources and institutions". Projet d'article pour les cahiers de l'ISMEA. Le Mans, 19 février. 2002.

CAETANO, M. R. e VALENTE, A. L. E. F. "Construção social de mercados diferenciados: da teoria ao estudo de caso da queijaria Alpina". XLVIII Congresso da Sociedade Brasileira de Economia, Administração e Sociologia Rural (SOBER), Campo Grande/MS, julho. Anais...2010.

CHALITA, M. A. N.; SILVA, D. da; PETTI, R. H. V. e SILVA, R. de O. P. "Análise sócio-cultural do consumo de queijos e sua relação com a alimentação: diálogos entre classes sociais, estilos de vida e mercados de qualidade". XLVIII Congresso da Sociedade Brasileira de Economia, Administração e Sociologia Rural (SOBER), Campo Grande/MS, julho. Anais...2010.

CHALITA, M. A. N. "A construção social e econômica do gosto e da preferência, o valor simbólico da mercadoria e o desempenho das exportações de cachaça". Informações Econômicas, v. 38, n 5, mai-2008.

EYMARD-DUVERNAY. "Conventions de qualité et formes de coordination". Revue Economique. L'économie des conventions. Presses de la Fondation Nationale des Sciences Politiques, v. 40, n. 2. mars-1989.

FERRAZ, J.; KUPFER, D. e HAGUENAUER, L. Made in Brazil: Desafios Competitivos para a Indústria. Campus: Rio de Janeiro. 1997. 
FERNANDES FILHO, J. F. e CAMPOS, F. R.. "A indústria rural no Brasil". Revista de Economia e Sociologia Rural, v. 41, n. 4.2003.

FISCHLER, C. "Raison et déraison dans les perceptions des risques alimentaires". Cahiers de Nutrition et de Diétetique, v. 33, n. 5, p. 297-301. 1990.

FISCHLER, C. "Frank Trentmann answers ten questions about economic sociology" (entrevista). Economic Sociology. The European Eletronic Newsletter, v. 7, n. 2, p. 22-25, feb.2006.

HAIR, J. F;ANDERSON, R. E.; TATHAM, R. L. e BLACK, W. C. Análise Multivariada de Dados. 6. ed. Porto Alegre: Bookman. 2009.

HOFF, D. N.; BRUCH, K. L. e PEDROZO, E. A. "Desenvolvimento de nichos de mercado para pequenos negócios: leite e laticínios de cabras e ovelhas em Bento Gonçalves, RS". Teoria e evidência econômica, Passo Fundo, v. 14, n. 28, p. 128-154, maio. 2007.

KARPIC, L. L'économie des singularités. Paris: Ed Gallimard. 2007.

MENEZES, S. de S. M. "A força dos laços de proximidade na tradição e inovação no/do território sergipano das fabriquetas de queijo". Tese de Doutoramento. Núcleo de
Pós-Graduação em Geografia, Universidade Federal de Sergipe, São Cristovão. 2009.

REZENDE, D. C. "Estratégia de coordenação e qualidade na cadeia dos queijos finos". Tese de Doutoramento. Instituto de Ciências Humanas e Sociais/UFRRJ. 2004.

VALCESCHI, E. e NICOLAS, F. In VALCESCHI, E. e NICOLAS, F. "La dynamique économique de la qualité agro-alimentaire". Agro-alimentaire: une économie de la qualité. INRA/Economie. 1995.

VITROLLLES, D.; MAFRA, L. e CERDAN, C. "Enjeux et perspectives de développement des Indications Géographiques au Brésil: une analyse à partir des deux produits de l'Etat de Minas Gerais." III Colloque Internacional du Réseau Syal - Systèmes Agroalimentaires Localisés. Alimentation et Territoires, ALTER. Anais...2006.

WILKINSON, J. "Economic and Agrofood studies en Brazil" Economic Sociology. The European Eletronic Newsletter, v. 11, n. 2, p. 3-9, mar-2010.

WILKINSON, J. "Sociologia econômica, a teoria das convenções e o funcionamento dos mercados: inputs para analisar os micro e pequenos empreendimentos agroindustriais no Brasil". Ensaios FEE, Porto Alegre, v. 23, n 2, p. 805-824. 2002. 